http://jmscr.igmpublication.org/home/ ISSN (e)-2347-176x ISSN (p) 2455-0450 crossref DOI: https://dx.doi.org/10.18535/jmscr/v9i3.37

\title{
Evaluation of Thickness of Buccal Attached Gingiva at Common Miniscrew Insertion Sites in Orthodontic Patients with Different Facial Types
}

\author{
Authors
}

\section{Dr Deval Choukhe ${ }^{1}$, Dr Sunil Kumar Pulluri²; Dr Shrinivas Ambarkar ${ }^{3}$ Dr Akash Lavate ${ }^{4}$, Dr Sneha Hoshing ${ }^{5}$, Dr Salman Shaikh ${ }^{6}$}

${ }^{1,6}$ PG Student, Department of Orthodontics and Dentofacial Orthopaedics, PDU Dental College Solapur

${ }^{2}$ Professor and HOD Department of Orthodontics and Dentofacial Orthopaedics, PDU Dental College Solapur

${ }^{3}$ Professor Department of Orthodontics and Dentofacial Orthopaedics, PDU Dental College Solapur

${ }^{4,5}$ Reader Department of Orthodontics and Dentofacial Orthopaedics, PDU Dental College Solapur

\begin{abstract}
Introduction: Gingival biotype has critical importance in determining the length and stability of miniscrew. This study was conducted to assessthickness of buccal attached gingiva at common miniscrew insertion sites in orthodontic patients with different facial types.

Material and Method: 60 orthodontic patients with no systemic disease and no transversal skeletal discrepancy were included in this study. All the subjects having healthy periodontium were considered. All subjects were within the age range of 18-25 years. Subjects were divided into three groups based on their Frankfort mandibular plane angle, namely; High angle, Normal angle, low angle respectively. Trans gingival probing was used to measure the thickness of the buccal attached gingiva. Endodontic spreader and digital vernier caliper were used to assess the gingival thickness. All measurements were recorded by the same examiner and data will be statistically analyzed.

Result: Results showed no statistically significant difference among the gingival thickness values of different facial types. No statistically significant difference found between male and female except in maxillary posterior region where males showed thicker biotype when compared to females.

Conclusion: No statistically significant difference was found between the thicknesses of maxillary and mandibular posterior buccal approximal attached gingiva and different facial types.

Keywords: Miniscrew, attached gingiva, vernier caliper, spreader.
\end{abstract}

\section{Introduction}

Anchorage conservation has always been the utmost necessity in orthodontics in order to achieve the desired results and it essentially determines the success of orthodontic treatment. Anchorage, defined as a resistance to unwanted tooth movement is a prerequisite for the orthodontic treatment of dental and skeletal malocclusions. ${ }^{1}$
Up until modern times, orthodontists have relied on conventional means of preserving anchorage by intraoral and extraoral devices, which had good patient compliance to prevent undesired tooth movement but intra oral anchorage appliances were ineffective in providing absolute anchorage. $^{2,3}$

Bobak et $\mathrm{al}^{4}$ concluded that transpalatal arch (TPA) was inefficient to modify orthodontic 
anchorage through modification of periodontal stresses.

In most studies on Nance appliance, some amount anchorage loss was inevitable, and inability of oral hygiene maintenance under the acrylic resin button resulted in inflammation of the soft tissue and decreased patient compliance. ${ }^{5,6}$ On the other hand, success with extraoral anchorage appliances like headgear completely relies on the patient acceptance and compliance therefore cannot be considered as a well-grounded source of anchorage. $^{7}$

The minutest force can lead to unwanted tooth movement, hence it is mandatory to have absolute anchorage in order to achieve acumen. Absolute anchorage is defined as no movement of the anchorage unit (zero anchorage loss) as a consequence to the reaction forces applied to move teeth, ${ }^{1}$ such an anchorage can only be attained by means of skeletal anchorage which includes all the devices that are fixed directly to the bone.

The revolutionary development of implants as a method of amplifying orthodontic anchorage (temporary anchorage devices; TADs), have become indispensable to the art and science of orthodontic treatment by overcoming the plausible shortcomings and acceptance problems of conventional intra oral and extra oral anchorage appliances. TADs are temporarily fixed within the bone with the purpose of escalating anchorage by supporting the teeth used as a part of anchor unit or by obviating the need for anchor unit completely. TADs are eventually removed once the goal is accomplished. They can be located transosteally, subperiosteally, or endosteally; and they can be fixed to bone either mechanically (cortically stabilized) or biochemically (osseointegrated). ${ }^{1}$

However, everything comes with its own set of limitations, which in case of TADs includes inflammation and infection of the soft tissue, injury to the adjacent structures and lack of initial stability. ${ }^{8,9}$ Initial stability is again dependant on multitude of factors such as the angulation of miniscrew to the bone, insertion torques, facial types, insertion sites, quality and quantity of cortical bone, length of miniscrew, and thickness of the gingiva. ${ }^{10,8,9}$

The interradicular miniscrew length ranges between 6-12 mm. ${ }^{11,12}$ Another important consideration is the thickness of the gingiva which varies in accordance to the anatomical site in the mouth which is further influenced by age, gender, growth and development, tooth shape and position and facial types. ${ }^{13}$ It has also been determined that the interradicular space between maxillary and mandibular second premolarfirst molars and firstsecond molars are the most appropriate anatomical sites for miniscrew insertion. ${ }^{14,15}$

This study was performed to investigate the thickness of the buccal approximal attached gingiva at common miniscrew insertion sites, which have critical importance in determining miniscrew length, in subjects with different facial types. The alternative (H1) hypothesis was that the thicknesses of buccalapproximal attached gingiva varies based on facial types.

\section{Material and Method}

The study was carried out at the Department of Orthodontics and Dentofacial Orthopaedics, Pandit Deendayal Upadhyay Dental College and Hospital, Solapur.60 orthodontic patients; 30 females and 30 males, with no systemic disease and no transversal skeletal discrepancy were included in this study. All the subjects having healthy periodontium were considered. The age of the subjects were between 18 to 25 years.

\section{Inclusion Criteria}

- No previous orthodontic treatment

- No transversal skeletal discrepancy,

- No systemic disease and related medication,

- No antibiotics medication within the last 6 months,

- No pregnancy and lactation, and

- No history of fixed or removable prosthodontics restorations. 


\section{Exclusion Criteria}

- Subjects with gingival swelling or destructive periodontal disease

- Severe posterior crowding

- Permanent teeth extraction, and ectopically positioned teeth

Periodontal evaluation of the subjects was performed from the mesial and distal surfaces of all teeth, using a periodontal probe (PQW7 Williams; Hu-Friedy, Chicago, Ill; Fig 1). Probing pocket depth were recorded. (Fig. 1)

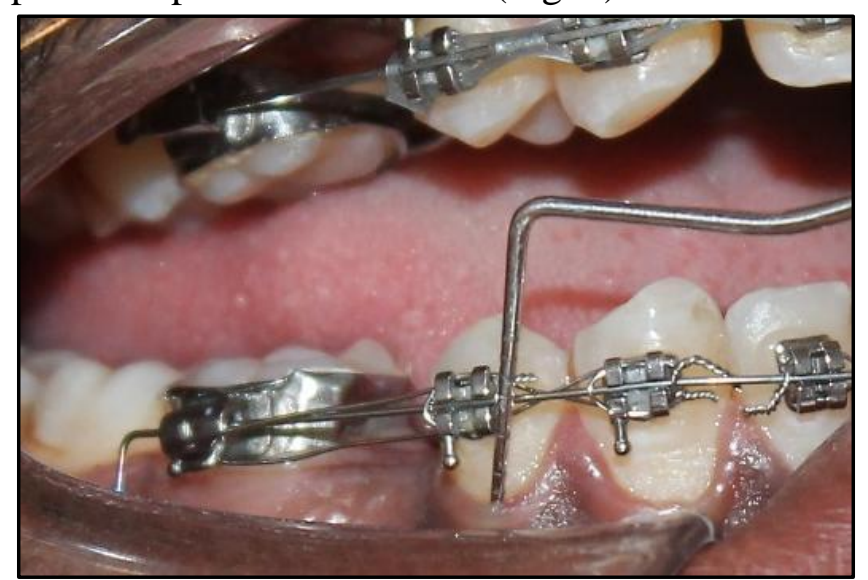

Fig.1

Lateral cephalometrics radiographs of the patients who are undergoing orthodontic treatment were collected. All the radiographs were obtained under standard conditions; the teeth were in centric occlusion with relaxed and closed lip position, the Frankfort horizontal plane parallel to the floor and the sagittal plane at right angles to the path of the X-ray. Frankfort Mandibular plane Angle was examined for assigning the subjects to a facial type.

The subjects were divided into three groups based on their Frankfort maxillary plane angle.

Group A- High angle,

Group B- Normal angle,

Group C- Low angle.

Thickness of the buccal attached gingiva was recorded by transgingival probing. $10 \mathrm{~mm}$ long Endodontic spreader with silicon stopper was taken. Before measurements Topical anesthetic gel was applied at the site of evaluation. Thickness of the buccal mucosa was measured from the common miniscrew insertion sites i.e., interradicular space between second premolar-first molar and first molar-second molar, in maxillary and mandibular archbilaterally respectively. Endodontic spreader was inserted perpendicularly in inter-radicular region approximately 5-7 mm above the cemento-enamel junction at common miniscrew insertion site.(Fig. 2) Spreader inserted in the gingiva until it hits the bone. Silicon Stopper was adjusted to be in contact with the gingiva. Endodontic spreader was removed carefully and readings were taken usinga digital vernier caliper from the silicon stopper to the tip of the endodontic spreader in order to assess the buccal thickness of attached gingiva.(Fig. 3) For each region all measurements was taken by same examiner in order to avoid bias.

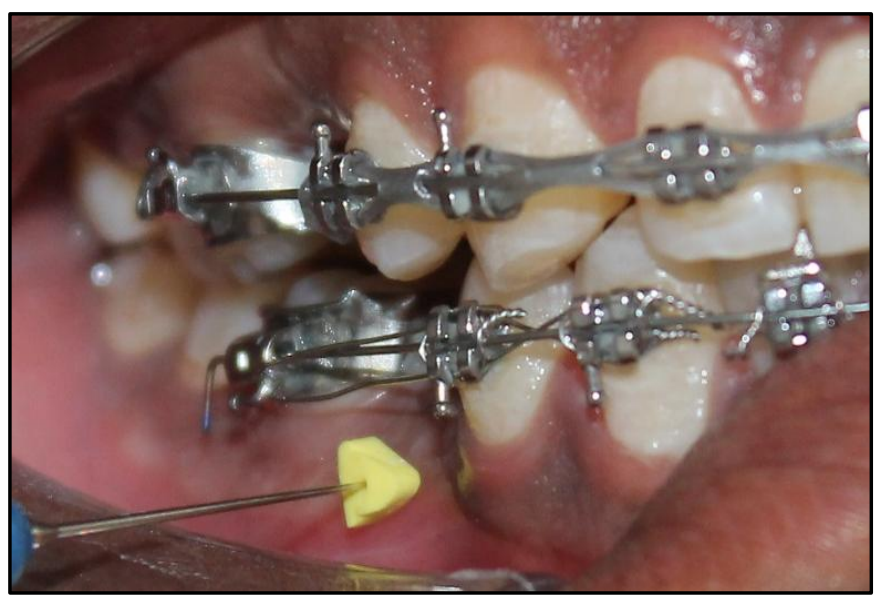

Fig. 2

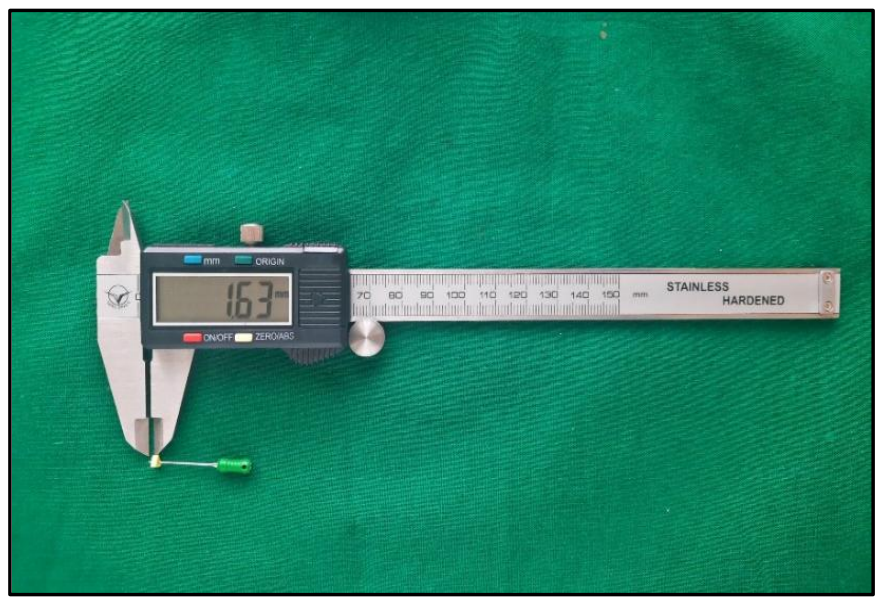

Fig. 3

\section{Statistical Analysis}

Statistical Product and Service Solutions (SPSS) version 21 for Windows (Armonk, NY:IBM corp software was used to analyse the data. Statistical analysis was done by using tools of descriptive 
statistics such as Mean, and SD for representing quantitative data. Probability $\mathrm{p}<0.05$, considered as significant as alpha error set at $5 \%$ with confidence interval of $95 \%$ set in the study. Power of the study was set at $80 \%$ with beta error set at $20 \%$. One-way ANOVA ' $F$ ' test was applied to compare periodontal parameter measurements among three groups in each gender. Post hoc data analysis which follows one way ANOVA test was done by using Tukeys multiple comparison test. Post hoc test analyses multiple pair -wise individual comparisons between three groups.

\section{Result}

Probing pocket depth measured periodontal evaluation was not statistically significant between the groups. (Table 1) Pocket probing Depth that was noted in the male subjects of group A had a mean probing depth of $1.75( \pm 0.1) \mathrm{mm}$, whereas female subjects of group A had a mean probing depth of $1.79( \pm 0.11) \mathrm{mm}$. Likewise pocket probing depth in the male subjects of group B had a mean probing depth of $1.83( \pm 0.09) \mathrm{mm}$, whereas female subjects of group B had a mean probing depth of $1.89( \pm 0.09) \mathrm{mm}$. Pocket probing depth in the male subjects of group $\mathrm{C}$ had a mean probing depth of $1.70( \pm 0.04) \mathrm{mm}$, whereas female subjects of group $\mathrm{C}$ had a mean probing depth of $1.68( \pm 0.06) \mathrm{mm}$. No highly significant difference was noted in the probing depth values of the three groups.

Table 1: Comparison of probing depth (in mm) between Group A (High Angle), Group B (Normal Angle) and Group C (Low Angle) respectively

\begin{tabular}{|l|c|c|}
\hline & $\begin{array}{c}\text { MALES } \\
\text { MEAN (SD) }\end{array}$ & $\begin{array}{c}\text { FEMALES } \\
\text { MEAN (SD) }\end{array}$ \\
\hline $\begin{array}{l}\text { Group A } \\
\text { (High Angle) }\end{array}$ & $1.75(0.1)$ & $1.79(0.11)$ \\
\hline $\begin{array}{l}\text { Group B } \\
\text { (Normal angle) }\end{array}$ & $1.83(0.09)$ & $1.83(0.09)$ \\
\hline $\begin{array}{l}\text { Group C } \\
\text { (Low angle) }\end{array}$ & $1.70(0.04)$ & $1.68(0.06)$ \\
\hline ANOVA F TEST & $\mathbf{F}=\mathbf{5 . 8 4 2}$ & $\mathbf{F}=7.263$ \\
\hline p value, Significance & $\mathbf{p}=\mathbf{0 . 0 0 8}$ & $\mathbf{p}=\mathbf{0 . 0 0 3}$ \\
\hline
\end{tabular}

In the maxillary arch, overall, males had the significantly thicker buccal approximal attached than females. However in the mandibular arch, thickness of the attached gingiva, showed no much difference between the two genders. Also, no statistically significant difference was found between the right and left side values of the same arch.

Overall, it was noted that maxillary arch had a thicker buccal attached gingiva than the mandibular arch.
The thickness of buccal attached gingiva in the maxillary arch of the males in the group $\mathrm{A}$ in the premolar region and in the first and second molar region was found to be $1.29-1.38 \mathrm{~mm}$ and 1.44 $1.49 \mathrm{~mm}$ respectively. Likewise in group B they were found to be $1.26-1.32 \mathrm{~mm}$ and $1.42 \mathrm{~mm}$ respectively; and in group C $1.21-1.24$ and 1.32 1.34 respectively. On intergroup comparison, highly statistically significant difference was found between group A and C. (Table 2) 
Table 2: Comparison of thickness of maxillary buccal attached gingiva between Group A (High Angle), Group B (Normal Angle) and Group C (Low Angle) respectively in males

\begin{tabular}{|c|c|c|c|c|}
\hline \multirow{3}{*}{ Males } & \multicolumn{4}{|c|}{ Maxilla } \\
\hline & \multicolumn{2}{|c|}{ RIGHT } & \multicolumn{2}{|c|}{ LEFT } \\
\hline & $\begin{array}{c}\text { 5-6 } \\
\text { MEAN (SD) }\end{array}$ & $\begin{array}{c}\text { 6-7 } \\
\text { MEAN (SD) }\end{array}$ & $\begin{array}{c}\text { 5-6 } \\
\text { MEAN (SD) }\end{array}$ & $\begin{array}{c}\text { 6-7 } \\
\text { MEAN (SD) }\end{array}$ \\
\hline $\begin{array}{l}\text { Group A } \\
\text { (High Angle) }\end{array}$ & $1.29(0.05)$ & $1.44(0.05)$ & $1.38(0.05)$ & $1.49(0.08)$ \\
\hline $\begin{array}{l}\text { Group B } \\
\text { (Normal angle) }\end{array}$ & $1.26(0.03)$ & $1.42(0.05)$ & $1.32(0.06)$ & $1.42(0.03)$ \\
\hline $\begin{array}{l}\text { Group C } \\
\text { (Low angle) }\end{array}$ & $1.24(0.05)$ & $1.34(0.01)$ & $1.21(0.07)$ & $1.32(0.02)$ \\
\hline ANOVA F TEST & $\mathbf{F}=\mathbf{2 . 7 9 8}$ & $\mathbf{F}=\mathbf{1 3 . 0}$ & $\mathbf{F}=\mathbf{1 5 . 3 9}$ & $\mathbf{F}=\mathbf{2 3 . 1 7}$ \\
\hline p value, Significance & $\mathbf{p}=\mathbf{0 . 0 7 9}$ & $\mathbf{p}<0.001 * *$ & $\mathrm{p}<0.001 * *$ & $\mathrm{p}<0.001 * *$ \\
\hline \multicolumn{5}{|c|}{ Tukey's post hoc test to find pairwise comparison } \\
\hline $\begin{array}{l}\text { Group A } \\
\text { vs Group B }\end{array}$ & $p=0.225$ & $p=0.40$ & $p=0.169$ & $\mathbf{p}=0.029 *$ \\
\hline $\begin{array}{l}\text { Group A vs } \\
\text { Group C }\end{array}$ & $\mathbf{p}=\mathbf{0 . 0 7 7}$ & $\mathbf{p}<0.001 * *$ & $\mathbf{p}<0.001 * *$ & $\mathbf{p}<0.001 * *$ \\
\hline Group B vs Group C & $\mathbf{p}=\mathbf{0 . 8 3 2}$ & $\mathbf{p}=\mathbf{0 . 0 0 3} *$ & $\mathbf{p}=0.004^{*}$ & $\mathrm{p}=0.001 *$ \\
\hline
\end{tabular}

The thickness of buccal attached gingiva in the mandibular arch of the males in the group $\mathrm{A}$ in the premolar region and in the first and second molar region was found to be $1.44-1.48 \mathrm{~mm}$ and 1.56 $1.68 \mathrm{~mm}$ respectively. Likewise in group B they were found to be $1.36-1.56 \mathrm{~mm}$ and $1.56-1.62$ mm respectively; and in group C $1.39-1.40$ and $1.49-1.59$ respectively. On intergroup comparison, no highly statistically significant difference was found between the groups. (Table 3)

Table 3: Comparison of thickness of mandibular buccal attached gingiva between -Group A (High Angle), Group B (Normal Angle) and Group C (Low Angle) respectively in males

\begin{tabular}{|c|c|c|c|c|}
\hline \multirow{3}{*}{ Males } & \multicolumn{4}{|c|}{ Mandible } \\
\hline & \multicolumn{2}{|c|}{ RIGHT } & \multicolumn{2}{|c|}{ LEFT } \\
\hline & $\begin{array}{c}5-6 \\
\text { MEAN (SD) }\end{array}$ & $\begin{array}{c}\text { 6-7 } \\
\text { MEAN (SD) }\end{array}$ & $\begin{array}{c}5-6 \\
\text { MEAN (SD) }\end{array}$ & $\begin{array}{c}\text { 6-7 } \\
\text { MEAN (SD) }\end{array}$ \\
\hline $\begin{array}{l}\text { Group A } \\
\text { (High Angle) }\end{array}$ & $1.48(0.06)$ & $1.68(0.04)$ & $1.44(0.07)$ & $1.56(0.06)$ \\
\hline $\begin{array}{l}\text { Group B } \\
\text { (Normal angle) }\end{array}$ & $1.39(0.09)$ & $1.62(0.07)$ & $1.36(0.04)$ & $1.56(0.04)$ \\
\hline $\begin{array}{l}\text { Group C } \\
\text { (Low angle) }\end{array}$ & $1.40(0.06)$ & $1.59(0.04)$ & $1.39(0.07)$ & $1.49(0.06)$ \\
\hline ANOVA F TEST & $F=4.078$ & $\mathbf{F}=6.999$ & $F=4.66$ & $\mathrm{~F}=\mathbf{4 . 8 5 3}$ \\
\hline p value, Significance & $\mathbf{p}=\mathbf{0 . 0 2 8} *$ & $\mathbf{p}=0.004 *$ & $\mathbf{p}=0.018 *$ & $\mathrm{p}=0.016^{*}$ \\
\hline \multicolumn{5}{|c|}{ Tukey's post hoc test to find pairwise comparison } \\
\hline $\begin{array}{l}\text { Group A } \\
\text { vs Group B }\end{array}$ & $\mathrm{p}=0.042 *$ & $\mathrm{p}=\mathbf{0 . 0 7 4}$ & $\mathbf{p}=\mathbf{0 . 0 1 5} *$ & $\mathbf{p}=\mathbf{0 . 9 8 2}$ \\
\hline $\begin{array}{l}\text { Group A vs } \\
\text { Group C }\end{array}$ & $p=0.062$ & $p=0.003 *$ & $p=0.147$ & $\mathbf{p}=\mathbf{0 . 0 2 5} *$ \\
\hline Group B vs Group C & $p=0.983$ & $p=0.347$ & $p=0.539$ & $\mathrm{p}=\mathbf{0 . 0 3 8}^{*}$ \\
\hline
\end{tabular}

The thickness of buccal attached gingiva in the maxillary arch of the females in the group A in the premolar region and in the first and second molar region was found to be $1.31-1.36 \mathrm{~mm}$ and 1.45 $1.50 \mathrm{~mm}$ respectively. Likewise in group B they were found to be $1.37-1.41 \mathrm{~mm}$ and $1.46-1.58$ $\mathrm{mm}$ respectively; and in group C $1.23-1.24$ and $1.31 \quad-1.33$ respectively. On intergroup comparison, highly statistically significant difference was found between group A and C. On 
intergroup comparison, highly statistically and C. (Table 4) significant difference was found between group B

Table 4: Comparison of thickness of maxillary buccal attached gingiva between Group A (High Angle), Group B (Normal Angle) and Group C (Low Angle) respectively in females

\begin{tabular}{|c|c|c|c|c|}
\hline \multirow{3}{*}{ Females } & \multicolumn{4}{|c|}{ Maxilla } \\
\hline & \multicolumn{2}{|c|}{ RIGHT } & \multicolumn{2}{|c|}{ LEFT } \\
\hline & $\begin{array}{c}\text { 5-6 } \\
\text { MEAN (SD) }\end{array}$ & $\begin{array}{c}\text { 6-7 } \\
\text { MEAN (SD) }\end{array}$ & $\begin{array}{c}\text { 5-6 } \\
\text { MEAN (SD) }\end{array}$ & $\begin{array}{c}\text { 6-7 } \\
\text { MEAN (SD) }\end{array}$ \\
\hline $\begin{array}{l}\text { Group A } \\
\text { (High Angle) }\end{array}$ & $1.31(0.03)$ & $1.45(0.05)$ & $1.36(0.06)$ & $1.50(0.06)$ \\
\hline $\begin{array}{l}\text { Group B } \\
\text { (Normal angle) }\end{array}$ & $1.41(0.1)$ & $1.58(0.21)$ & $1.37(0.06)$ & $1.46(0.08)$ \\
\hline $\begin{array}{l}\text { Group C } \\
\text { (Low angle) }\end{array}$ & $1.23(0.02)$ & $1.33(0.02)$ & $1.24(0.02)$ & $1.31(0.04)$ \\
\hline ANOVA F TEST & $\mathbf{F}=18.910$ & $\mathbf{F}=\mathbf{1 0 . 2 5 5}$ & $\mathbf{F}=\mathbf{1 7 . 0 5}$ & $\mathbf{F}=\mathbf{2 2 . 8 2}$ \\
\hline p value, Significance & $\mathbf{p}<0.001 * *$ & p $<0.001 * *$ & p $<0.001 * *$ & p $<0.001 * *$ \\
\hline \multicolumn{5}{|c|}{ Tukey's post hoc test to find pairwise comparison } \\
\hline $\begin{array}{l}\text { Group A } \\
\text { vs Group B }\end{array}$ & $\mathrm{p}=0.008^{*}$ & $p=0.067$ & $\mathbf{p}=\mathbf{0 . 9 2 9}$ & $p=0.342$ \\
\hline $\begin{array}{l}\text { Group A vs } \\
\text { Group C }\end{array}$ & $\mathbf{p}=\mathbf{0 . 0 2} *$ & $\mathbf{p}=0.009 *$ & $\mathbf{p}<0.001 * *$ & $\mathbf{p}<0.001 * *$ \\
\hline Group B vs Group C & p < $0.001 * *$ & $\mathbf{p}<0.001 * *$ & p < $0.001 * *$ & $\mathbf{p}<0.001 * *$ \\
\hline
\end{tabular}

The thickness of buccal attached gingiva in the mandibular arch of the females in the group A in the premolar region and in the first and second molar region was found to be $1.44-1.46 \mathrm{~mm}$ and $1.54-1.66 \mathrm{~mm}$ respectively. Likewise in group B they were found to be $1.37-1.41 \mathrm{~mm}$ and $1.56-$
$1.65 \mathrm{~mm}$ respectively; and in group C $1.37-1.38$ and $1.46-1.59$ respectively. On intergroup comparison, no highly statistically significant difference was found between the groups. (Table $5)$.

Table 5: Comparison of thickness of mandibular buccal attached gingiva between Group A (High Angle), Group B (Normal Angle) and Group C (Low Angle) respectively in females

\begin{tabular}{|c|c|c|c|c|}
\hline \multirow{3}{*}{ Females } & \multicolumn{4}{|c|}{ Mandible } \\
\hline & \multicolumn{2}{|c|}{ RIGHT } & \multicolumn{2}{|c|}{ LEFT } \\
\hline & $\begin{array}{c}\text { 5-6 } \\
\text { MEAN (SD) }\end{array}$ & $\begin{array}{c}\text { 6-7 } \\
\text { MEAN (SD) }\end{array}$ & $\begin{array}{c}\text { 5-6 } \\
\text { MEAN (SD) }\end{array}$ & $\begin{array}{c}\text { 6-7 } \\
\text { MEAN (SD) }\end{array}$ \\
\hline $\begin{array}{l}\text { Group A } \\
\text { (High Angle) }\end{array}$ & $1.46(0.05)$ & $1.66(0.05)$ & $1.44(0.1)$ & $1.54(0.04)$ \\
\hline $\begin{array}{l}\text { Group B } \\
\text { (Normal angle) }\end{array}$ & $1.41(0.1)$ & $1.65(0.04)$ & $1.37(0.02)$ & $1.56(0.04)$ \\
\hline $\begin{array}{l}\text { Group C } \\
\text { (Low angle) }\end{array}$ & $1.38(0.05)$ & $1.59(0.04)$ & $1.37(0.06)$ & $1.46(0.08)$ \\
\hline ANOVA F TEST & $F=2.808$ & $\mathbf{F}=7.317$ & $\mathbf{F}=3.301$ & $F=6.934$ \\
\hline p value, Significance & $\mathbf{p}=\mathbf{0 . 0 7 8}$ & $\mathbf{p}=0.003^{*}$ & $\mathbf{p}=\mathbf{0 . 0 5 2}$ & $\mathbf{p}=\mathbf{0 . 0 0 4} *$ \\
\hline \multicolumn{5}{|c|}{ Tukey's post hoc test to find pairwise comparison } \\
\hline $\begin{array}{l}\text { Group A } \\
\text { vs Group B }\end{array}$ & $p=0.315$ & $p=0.728$ & $p=0.085$ & $p=0.849$ \\
\hline $\begin{array}{l}\text { Group A vs } \\
\text { Group C }\end{array}$ & $p=0.067$ & $\mathbf{p}=0.003 *$ & $\mathbf{p}=\mathbf{0 . 0 8 5}$ & $\mathbf{p}=0.019 *$ \\
\hline Group B vs Group C & $p=0.670$ & $\mathbf{p}=0.021 *$ & $\mathbf{p}=\mathbf{1 . 0 0 0}$ & $\mathbf{p}=0.005^{*}$ \\
\hline
\end{tabular}




\section{Discussion}

In recent times, there has been an increased tendency of researchers to focus on thickness of different parts of masticatory mucosa, especially gingival thickness has gained considerable importance in dentistry from both an epidemiologic and a therapeutic point of view. ${ }^{13}$ Thickness of attached gingiva play very vital role for success of miniscrews. Stability of the miniscrew is greatly influenced by many factors in oral cavity. Miniscrews are inserted between the between the roots and it has close proximity to the gingiva, compact bone, cancellous bone. ${ }^{16}$ Aim of the present study was to determine the thicknesses of the buccal attached gingiva between the maxillary and mandibular second premolar-first molar and first-second molars at common miniscrew insertion sites, in subjects with different facial types.

Gingival inflammation can occur following the insertion of miniscrew which possess high risk of implant failure. Although miniscrew inserted within the width of attached gingiva shows highest success rate as compared to when placed in other parts of gingiva. ${ }^{11}$ There are several ways by which transgingival probing can be done to assess the gingival thickness. One of them being the use of injection needle and probe. In few studies conducted by Claffet et al and Olsson et al; the thickness of the attached gingiva is measured by using injection needle and probe. In their studies, gingival thickness was assessed from 6 teeth in maxillary and mandibular anterior region. The results of the current study were supported in literature by a study conducted by Kolte et al ${ }^{19}$ which reported no significant difference between genders in the mandible but significantly greater gingival thickness in males in the maxilla.

Yet another study conducted by Muller ${ }^{20}$, found the gingiva to be thicker in the maxilla than in the mandible, with the thinnest facial gingiva found at maxillary canines as well as mandibular 1st premolar region.

Ozer Alkan et ${ }^{21}$ al concluded that the thicknesses of maxillary and mandibular posterior buccal approximal attached gingiva varied between 1.18$1.72 \mathrm{~mm}$. Therefore, in order to achieve maximum stability of the miniscrew, they should be inserted at this point at a depth of 7-8 mm. No statistically significant difference was found between subjects with different facial types.

Yet another method of gingival thickness assessment is by the use of ultrasonic devices. Several studies have been carried out using this method; among these include, Cha et $\mathrm{al}^{22}$ who found that there is no statistically significant difference between the two genders with respect to mandible, while it was higher in male with respect to maxilla for four areas between centrallateral incisors, lateral incisor-canine, canine-first premolar, and second premolar-first molar. Also Parmar et $\mathrm{al}^{8}$ found that males have thicker attached gingiva between first and second molar and females has thicker gingiva between the canine- first premolar region. These results support findings from our study that showed no statistically significant difference between the two genders except in the maxilla, where males had significantly thicker buccal approximal attached gingiva than the females in the right second premolar-first molar region.

\section{Conclusion}

1) No statistically significant difference was found between the thicknesses of maxillary and mandibular posterior buccal approximal attached gingiva amongst different facial types.

2) No statistically significant difference was found between the gingival thicknesses amongst the two genders, except in the maxillary posterior region.

3) Males showed statistically significant higher values of gingival thickness in the maxillary posterior region when compared to females.

\section{Reference}

1. Cope JB. Temporary anchorage devices in orthodontics: A paradigm shift. Semin 
Orthod. 2005;11(1 SPEC. ISS.):3-9.

2. Pilon JJ, Kuijpers-Jagtman AM, Maltha JC. Magnitude of orthodontic forces and rate of bodily tooth movement. An experimental study. Am J Orthod Dentofacial Orthop. 1996;110(1):16-23.

3. Weinstein S, Haak DC, Morris LY, Snyder BB, Attaway HE. On equilibrium theory of tooth position. Angle Orthod 26. 1963;33(1):1-26.

4. Bobak V, Christiansen RL, Hollister SJ, Kohn DH. Stress-related molar responses to the transpalatal arch: a finite element analysis. Am J Orthod Dentofacial Orthop. 1997;112(5):512-8.

5. Kyung H-M, Park H-S, Bae S-M, Sung JH, Kim L-B. Development of orthodontic micro-implants for intraoral anchorage. $\mathrm{J}$ Clin Orthod. 2003;37(6):321-8.

6. Chen F, Terada K, Handa K. Anchorage effect of various shape palatal osseointegrated implants: A finite element study. Angle Orthod. 2005;75(3):378-85.

7. Egolf RJ, BeGole EA, Upshaw HS. Factors associated with orthodontic patient compliance with intraoral elastic and headgear wear. Am J Orthod Dentofac Orthop. 1990;97(4):336-48.

8. Parmar R, Reddy V, Reddy SK, Reddy D. Determination of soft tissue thickness at orthodontic miniscrew placement sites using ultrasonography for customizing screw selection. Am J Orthod Dentofac Orthop. 2016 Oct 1;150(4):651-8.

9. Papageorgiou SN, Zogakis IP, Papadopoulos MA. Failure rates and associated risk factors of orthodontic miniscrew implants: A meta-analysis. Am J Orthod Dentofac Orthop [Internet]. 2012;142(5):577-595.e7. Available from: http://dx.doi.org/10.1016/j.ajodo.2012.05.0 16

10. Papadopoulos MA, Tarawneh F. The use of miniscrew implants for temporary skeletal anchorage in orthodontics: A comprehensive review. Oral Surgery, Oral Med Oral Pathol Oral Radiol Endodontology. 2007;103(5):6-15.

11. Deguchi T, Nasu M, Murakami K, Yabuuchi T, Kamioka H, TakanoYamamoto T. Quantitative evaluation of cortical bone thickness with computed tomographic scanning for orthodontic implants. Am J Orthod Dentofac Orthop. 2006;129(6):721.e7-721.e12.

12. Yi Lin S, Mimi Y, Ming Tak C, Kelvin Weng Chiong F, Hung Chew W. A study of success rate of miniscrew implants as temporary anchorage devices in Singapore. Int J Dent. 2015;2015.

13. Vandana KL, Savitha B. Thickness of gingiva in association with age, gender and dental arch location. J Clin Periodontol. 2005;32(7):828-30.

14. Monnerat C, Restle L, Mucha JN. Tomographic mapping of mandibular interradicular spaces for placement of orthodontic mini-implants. Am J Orthod Dentofac Orthop [Internet]. 2009; 135(4):428.e1-428.e9. Available from: http://dx.doi.org/10.1016/j.ajodo.2008.06.0 24

15. Fayeda MMS, Pazerab P, Katsarosc C. Optimal sites for orthodontic mini-implant placement assessed by cone beam computed tomography. Angle Orthod. 2010;80(5):939-51.

16. Baumgaertel S. Hard and soft tissue considerations at miniimplant insertion sites. J Orthod. 2014;41:S3-7.

17. Claffey N, Shanley D. Relationship of gingival thickness and bleeding to loss of probing attachment in shallow sites following nonsurgical periodontal therapy. J Clin Periodontol. 1986;13(7):654-7.

18. Olsson M, Ljndhe J, Marinello CP. On the relationship between crown form and clinical features of the gingiva in adolescents. 1993;(i):570-7.

19. Rajashri Kolte, Abhay Kolte AM. 
Assessment of gingival thickness with regards to age, gender and arch location. $\mathbf{J}$ Indian Soc Periodontol. 2014;18(4):47881.

20. Müller HP, Heinecke A, Schaller N, Eger T. Masticatory mucosa in subjects with different periodontal phenotypes. J Clin Periodontol. 2000;27(9):621-6.

21. Alkan Ö, Kaya Y. The thickness of posterior buccal attached gingiva at common miniscrew insertion sites in subjects with different facial types. Am $\mathbf{J}$ Orthod Dentofac Orthop. 2019 Dec 1;156(6):800-7.

22. Cha BK, Lee YH, Lee NK, Choi DS, Baek SH. Soft tissue thickness for placement of an orthodontic miniscrew using an ultrasonic device. Angle Orthod. 2008;78(3):403-8. 